\title{
(t)
}

\section{REFLEXÕES SOBRE A DIMENSÃO TÉCNICO-OPERATIVA NA FORMAÇÃO EM SERVIÇO SOCIAL}

\author{
Reflections on the dimension technical-operative in professional \\ qualification in Social Work
}

\section{Priscila Fernanda Gonçalves Cardos Doroth de Assis Schimidt Doi ${ }^{2}$}

\begin{abstract}
RESUMO
O presente artigo é uma produção de duas autoras que observavam inquietas diversos profissionais expressarem suas dificuldades no que diz respeito a dimensão técnico-operativa no seu cotidiano profissional. Longe da pretensão de esgotar tal questão, o artigo apresenta os desafios presentes na discussão da dimensão técnico-operativa do Serviço Social no âmbito da formação profissional. Sendo o Serviço Social uma profissão interventiva, a formação profissional deve preocupar-se em preparar profissionais para uma intervenção qualificada e politicamente direcionada. Por meio de pesquisa bibliográfica, as autoras refletem sobre a frequente cisão entre pensar, agir e escolher presente na compreensão de estudantes e profissionais, tanto no contexto da academia quanto no âmbito do exercício profissional, apresentando possíveis maneiras de consolidar a compreensão de unidade entre as dimensões do trabalho profissional na lógica curricular em Serviço Social.
\end{abstract}

\section{PALAVRAS-CHAVE}

Serviço Social. Dimensão Técnico-Operativa. Trabalho Profissional. Formação Profissional em Serviço Social.

'Doutora em Serviço Social pela Pontífica Universidade Católica de São Paulo(PUC) SP, São Paulo, SP, Brasil). Professora da Universidade Federal de São Paulo (UNIFESP Baixada Santista, Santos, SP, Brasil). E-mail: <prifgcardoso@gmail.com>. ${ }^{2}$ Graduada em Serviço Social pela Universidade Federal de São Paulo (UNIFESP Baixada Santista, Santos, SP, Brasil). Assistente Social da Prefeitura Municipal de Indaiatuba (PMI, Indaiatuba, SP, Brasil). E-mail: <doroth_assis@hotmail.com>. 


\begin{abstract}
This article is a production of two authors who observed several professionals restless express their difficulties with regard to technical and operational dimension in their daily work. Far from intending to exhaust this question, the article presents the challenges present in the discussion of the technical and operational dimension of social work in professional qualification. Being Social Services an interventional profession, professional qualification should concern in preparing professionals for a qualified and politically targeted intervention. Through literature, the authors reflect on the frequent split between thinking, acting and choose this understanding of students and professionals, both within academia and in the scope of professional practice, with possible ways to consolidate the understanding of unity among the dimensions of professional work in the curricular logic in Social work.
\end{abstract}

\title{
KEYWORDS
}

Social Services, Dimension Technical Operations, Professional Work, Professional qualification in Social Work.

Submetido em: 15/9/2016

Aceito em: 21/6/2017

\section{INTRODUÇÃO}

Duas gerações movidas por uma mesma inquietação: como discutir a questão da dimensão técnico-operativa na formação em Serviço Social? Estamos formando profissionais capacitados ética, técnica e politicamente para o exercício profissional? Sendo o Serviço Social uma profissão interventiva, como dar conta da preparação do profissional para seu trabalho sem perder de vista o refletir e o escolher em sua ação?

Essas são algumas das questões que provocaram a elaboração deste artigo, a partir de pesquisa teórica, com a realização de revisão bibliográfica (MARCONI; LAKATOS, 1992) com levantamento das publicações que versavam sobre o tema nos últimos dez anos. Destacamos as produções 3 de Guerra (1995); Santos (2006, 2010); Santos e Pini (2013); Santos, Backx e Guerra (2012) e buscamos

\footnotetext{
${ }^{3}$ Após pesquisa bibliográfica, podemos afirmar que a produção teórica a respeito desta temática é escassa ganhando densidade, numa perspectiva crítica, a partir de meados dos anos 2.000, sendo ainda poucos os pesquisadores que produzem sobre a mesma.

${ }^{4}$ A referida obra, intitulada "A dimensão técnico-operativa no Serviço Social: desafios contemporâneos" contém coletânea de textos de diferentes autores elaborado para simpósio em Juiz de Fora que buscou contribuir com a produção teórica e bibliográfica relacionada à dimensão técnico-operativa do Serviço Social. Neste sentido, foram analisados aqui também Sarmento, Souza Filho,
} 
realizar uma síntese analítica sobre o tema apresentando os desafios postos a esta discussão no que se refere a formação profissional. Longe de trazer respostas prontas, apresentamos aqui algumas inquietações sobre uma temática que, desde meados da década de 1990, vem ganhando mais espaço no seio do Serviço Social e, ao nosso entender, parece questão ainda não resolvida.

Em 1998, lamamoto já apresentava o desafio posto ao Serviço Social brasileiro e à sua produção teórica no que se refere à criação de subsídios para pensarmos a formação e o exercício profissional:

O grande desafio na atualidade é, pois, transitar da bagagem teórica acumulada ao enraizamento da profissão na realidade, atribuindo, ao mesmo tempo, uma maior atenção às estratégias, táticas e técnicas do trabalho profissional, em função das particularidades dos temas que são objeto de estudo e ação do Assistente Social (IAMAMOTO, 1998, p. 52).

Passados quase vinte anos de tal afirmação, não é incomum escutarmos profissionais e estudantes apresentando sua dificuldade no que se refere ao uso dos instrumentais e a realização de seu trabalho no tensionamento entre as demandas postas pela instituição, a realidade apresentada pelos usuários e a intencionalidade e compromisso ético-político de sua intervenção.

Diferentes produções ${ }^{5}$ vêm registrando esta dificuldade, que muitas vezes é traduzida pelo profissional como uma sensação de despreparo para o exercício profissional.

\begin{abstract}
É recorrente a manifestação de insatisfação dos profissionais com sua formação (na graduação), na perspectiva da preparação para este 'fazer', especialmente neste momento de implantação de políticas, como por exemplo, o Sistema Único de Assistência Social (SUAS), que determina que as ações profissionais devem ter centralidade na família.
\end{abstract}

Trindade e Eiras presentes nesta obra.

${ }^{5}$ Diversos capítulos da obra organizada por Santos, Backx e Guerra (2012), tanto aqueles que serviram de subsídio teórico para os eixos do evento quanto aqueles que registram os debates realizados, deixam evidente que os profissionais vivenciam tal inquietude. Também não é incomum encontrarmos este registro em comunicações apresentadas por professores e/ou profissionais (que atuam nas diferentes políticas sociais) em congressos da categoria. 
Diante dos desafios encontrados, os assistentes sociais interpretam como suas as dificuldades, qualificando-as como falta de habilidade ou de capacidade técnica para criar, executar, ou manusear instrumentos e técnicas, que se traduzem numa busca incessante pelo aprendizado ou a descoberta de 'fórmulas' para este 'fazer'. (VICENTE; CARDOSO, 2010, não paginado).

A busca por metodologias de ação, manuais de intervenção, técnicas e instrumentos para o trabalho com grupos ou mesmo o manuseio de instrumentais há anos utilizados pela profissão no atendimento individual, são cada vez mais recorrentes entre os profissionais e estagiários que muitas vezes não se sentem suficientemente preparados para o cotidiano do trabalho profissional.

Também é interessante destacar, neste introito, o constante 'apelo' por 'respostas' acerca dessa dimensão interventiva por parte dos estudantes de graduação, pós-graduação e de profissionais que estão atuando na área de Serviço Social. Isto sinaliza que ainda é uma discussão teórica e prática em aberto, rica de possibilidades, dicotomias e contradições, mas que precisa receber um tratamento investigativo e produtivo para que não seja desqualificada por princípio (SARMENTO, 2012, p. 103).

Na trajetória do Serviço Social, nota-se que essa questão terá maior ou menor importância em cada período. Concordamos com lamamoto (1998) e Cardoso (2013) sobre as ênfases vividas nos processos políticos e formativos da profissão em sua história: a ênfase na dimensão técnico-operativa trazendo uma perspectiva praticista, a ênfase na dimensão teórico-metodológica apresentando uma perspectiva teoricista e a ênfase na dimensão ético-política constituindo uma perspectiva politicista da profissão. Tais ênfases e perspectivas terão maior espaço em cada um dos diferentes projetos e momentos da profissão.

Ao longo do tempo, têm sido observados equívocos no tratamento da dimensão técnicooperativa, tanto no que tange à formação quanto no que tange ao exercício profissional. Um rápido olhar sobre a historiografia da profissão mostra que, na década de 1970, delegava-se 
a essa dimensão a responsabilidade exclusiva pela competência profissional, em especial, aos instrumentos e técnicas; já na década de 1980, ela passa a um segundo plano, atribuindo-se apenas ao conhecimento teórico a responsabilidade pela competência profissional (SANTOS; BACKX; GUERRA, 2012, p. 11).

Superestimar ou subestimar qualquer uma dessas dimensões parece-nos um equívoco que reduz a compreensão do trabalho profissional ao invés de entendê-lo em sua totalidade, reduzindo consequentemente, a construção de possibilidades concretas e competentes para o exercício e a formação profissional.

[...] o teórico-metodológico, o ético-político e o técnico-operativo - são fundamentais e complementares entre si. Porém, aprisionados em si mesmos transformam-se em limites que vêm tecendo o cenário de algumas das dificuldades, identificadas pela categoria profissional, que necessitam ser ultrapassadas: o teoricismo, o militantismo e o tecnicismo (IAMAMOTO, 1998, p. 53).

$\mathrm{Na}$ tentativa de romper com as perspectivas tecnicistas, teoricistas e politicistas o novo projeto de formação, expresso nas diretrizes curriculares de $1996^{6}$, buscará retomar uma formação que possibilite ao profissional desenvolver competência técnico-operativa, teóricometodológica e ético-política. A discussão do exercício profissional e, mais especificamente da dimensão técnico-operativa, começará ganhar a preocupação teórica de profissionais ligados à docência e a produção do conhecimento, não tendo, no entanto, nem de longe se esgotado. "A despeito desses novos pilares, pode-se dizer que são incipientes ainda a produção acadêmica e a organização de fóruns de debates da profissão voltados para as reflexões sobre a dimensão técnico-operativa" (SANTOS; BACKX; GUERRA, 2012, p. 11).

Assim, buscamos neste artigo, contribuir com este rico e necessário debate, pensando-o especialmente, no que se refere à formação profissional e seus desafios na construção de uma intervenção

\footnotetext{
${ }^{6}$ Referimo-nos as Diretrizes Curriculares como sendo de 1996, entendendo que nossa referência é o documento aprovado pela ABEPSS e pela categoria neste ano, mesmo que a aprovação destas oficialmente tenha se dado (com significativos cortes) apenas em 2002 estando expressas na Resolução CNE/CES nº 15.
} 
profissional crítica e reflexiva, repleta de possibilidades de pensar, fazer e escolher com clareza de intencionalidades e elaboração de estratégias e táticas no cotidiano profissional. Desse modo, fazemos coro com Sarmento: "[...] defendo que não reconheço uma profissão interventiva (como a do Serviço Social) que prescinda desta discussão, e vejo que nunca é tarde para provocá-la de forma intensa e o mais qualificada possível" (SARMENTO, 2012, p. 104).

\section{A DIMENSÃO TÉCNICO-OPERATIVA DO TRABALHO PROFISSIONAL NA SUA RELAÇÃO COM AS DEMAIS DIMENSÕES}

Pensar a dimensão técnico-operativa é indissociável da reflexão sobre as dimensões teórico-metodológica e ético-política, pois, em nossa compreensão, trata-se de uma unidade-diversa ${ }^{7}$ que constitui o trabalho profissional na relação direta com as condições objetivas e subjetivas deste trabalho.

[...] a dimensão técnico-operativa é constituída dos seguintes elementos: as estratégias e táticas definidas para orientar a ação profissional, os instrumentos, técnicas e habilidades utilizadas pelo profissional, o conhecimento procedimental necessário para a manipulação dos diferentes recursos técnico-operativos, bem como, a orientação teórico-metodológica e ético-política dos agentes profissionais (SANTOS; SOUZA FILHO; BACKX, 2012, p. 21).

Explicitemos um pouco mais cada uma dessas dimensões e a unidade que conformam.

Entendemos que o trabalho do assistente social é uma das práxis realizadas pelo homem e, assim, um processo de objetivação do ser social. O homem, como ser social, diferencia-se do ser natural através de seu trabalho, no qual, a partir de suas necessidades, transforma a natureza, objetivando-se no seu produto final ${ }^{8}$.

Marx, ao tratar do trabalho humano, mostra como a atividade do homem é atividade que se desenvolve

\footnotetext{
7 "A formação de uma totalidade a partir da unidade entre distintos elementos que, justamente em suas especificidades e diferenças, conformam tal unidade. Elementos que se complementam nas suas diferenças sendo interdependentes ao serem compreendidos como unidade" (CARDOSO, 2013, p. 64).

8 Sobre esta discussão ver: Netto e Braz (2006) e Lessa (1999).
} 
de acordo com finalidades que, à sua vez, só existem através do homem como produto de sua consciência - ainda que seja uma certa consciência da finalidade - e como liberdade de escolha entre alternativas - ainda que seja uma certa liberdade de escolha entre determinadas alternativas. Mediante o processo de trabalho, pode objetivar-se no mundo como ser capaz de formular escolhas e como tal é potencialmente livre e criativo. Dispondo de capacidade teleológica, projetiva, consciente, o ser social se põe capaz de liberdade (PAIXÃO, 1997, p. 65-66).

Para realizar sua produção, o homem realiza um processo de antecipação, idealização daquilo que no real será produzido (o que por si só, não garante que o resultado dessa ação se dê conforme projetado). Assim, para efetivar sua ação, o assistente social está realizando o processo de uma prévia ideação, uma antecipação; ou seja, essa ação tem como pressuposto uma dada finalidade, que é posta pelo indivíduo9.

Essa ação terá, portanto, uma intencionalidade que é informada por componentes ideo-políticos, o que chamamos de dimensão éticopolítica. Trata-se de uma opção, que envolve sempre a realização de uma escolha, que parte de uma determinada visão de homem, de mundo e de sociedade, informada por valores ético-políticos que direcionam essa ação, apontando para um projeto de sociedade.

Nesse contexto, destacamos que - independente de uma consciência crítica dos sujeitos - todas as ações profissionais são norteadas por intencionalidades políticas que, em última instância, fortalecem um entre os dois movimentos mais genéricos: o de conservação ou ruptura com a ordem social vigente (CARDOSO, 1999).

As respostas profissionais serão dadas, portanto, a partir das razões e vontades que orientam a intencionalidade da ação do profissional na sua relação com as condições objetivas para tal. Porém, essas razões e vontades que compõem a intencionalidade do trabalho profissional necessitam, e estão baseadas, em

\footnotetext{
9 É necessário destacar aqui, que tal finalidade está direcionada pela intencionalidade da ação e estas (finalidade e intencionalidade) são sempre produto das condições objetivas e subjetivas que envolvem o profissional e seu trabalho
} 
explicações e interpretações que fundamentam os valores éticopolíticos que a informam.

A visão de homem, de mundo e de sociedade é construída por: a) uma base que explique e interprete a sociedade, seu modo de constituir-se e os possíveis caminhos de intervenção nessa realidade para sua manutenção ou transformação, de acordo com sua intencionalidade; b) um método de análise da realidade, por sua vez, constitutivo de uma teoria social relacionada aos componentes ideo-políticos, conforme acima mencionados. A isto chamamos de dimensão teórico-metodológica.

A elaboração teórica diz respeito ao entendimento e à interpretação das conexões, relações, vínculos das coisas entre si. A teoria é o que possibilita e constitui essa apreensão, "[...] para Marx, [é] a reprodução ideal do movimento real do objeto [...]" (NETTO, 2011, p. 21). Podemos, portanto, afirmar que a teoria informa a prática, que é elemento constitutivo da teoria. "Pensar y ser, por tanto, aunque difieran, forman al mismo tiempo una unidad el uno con el otro" (MARX; ENGELS, 1987, p. 620, grifo dos autores). ${ }^{10}$

Aopção pela incorporação dos referenciaisteórico-metodológicos, ou seja, de um método, de uma determinada teoria, nos apresenta a unidade entre essas duas dimensões - a dimensão ético-política e a dimensão teórico-metodológica - pois ao buscar explicações em determinada teoria há a opção por uma teoria que esteja de acordo com a intencionalidade da ação profissional, ao mesmo tempo em que essa intencionalidade está pautada em uma dada concepção sobre as coisas e o mundo.

Da mesma maneira, a forma de entender e explicar a realidade demonstrar as relações, os vínculos e conexões existentes entre as coisas-, também está imbuída de componentes ídeo-políticos, se partirmos do suposto da não neutralidade da teoria, e do fato de que toda teoria tem em si a defesa de um ponto de vista na sociedade, em nosso entendimento, a defesa de um projeto societário.

Para que a ação se concretize na relação com essas duas dimensões, entram os componentes técnico-operativos que dão concretude

${ }_{10}$ Tradução livre: "Pensar e ser, portanto, mesmo que se diferenciem, formam ao mesmo tempo uma unidade de um com o outro". 
às outras duas dimensões, possibilitando a finalização do que foi antecipado anteriormente, mesmo que, muitas vezes se tenha um produto final diferenciado do idealizado.

A terceira dimensão que chamamos de dimensão técnico-operativa, diz respeito, portanto, ao modo de concretizar-se da ação profissional, à forma como a intencionalidade e a abstração se apresentarão no real.

[...] A dimensão técnico-operativa se constitui na 'forma de aparecer da profissão', no modo pelo qual a profissão é conhecida e reconhecida. Ela é o modo de ser da profissão, o modo como aparece no movimento das três dimensões. Tal característica permitiria reconhecê-la até mesmo como uma 'síntese' do exercício profissional, pois é composta também pelo conhecimento da categoria, pelas qualidades subjetivas dos agentes, pelas condições objetivas do trabalho, pelo projeto profissional, pela ética, pelos valores. Portanto, discutí-la significa discutir o trabalho profissional como um todo, implica discutir o trabalho profissional como resultado de tal trabalho (SANTOS; SOUZA FILHO; BACKX, 2012, p. 17).

Para concretizarmos um pouco mais tal unidade, tentemos, didaticamente, pensar essa ação profissional a partir de três questões: o que/como fazer?, por que fazer? e para que fazer?.

- Para que fazer? A resposta desta questão explicita ao profissional a intencionalidade de sua ação, conferindo sentido à esta. Aponta onde ele quer chegar com a realização desse fazer, ou seja, a direção social que imprimirá à sua ação orientando as escolhas que realizará. Diz respeito, portanto, a dimensão ético-política.

- Por que fazer? Diz respeito a forma como o profissional compreende reflexivamente sua ação e o objeto/sujeito desta, justificando a necessidade de tal intervenção e o caminho escolhido para esta. Os aportes teóricometodológicos que sustentam sua análise e sua intervenção orientando, informando e explicitando todas as intencionalidades contidas nesta. $O$ que nos remete $a$ dimensão teórico-metodológica. 
- O que/como fazer? Está diretamente relacionada ao cotidiano na sua operacionalização, a realização em si de suas atividades, porém depende completamente das respostas dadas às outras duas questões e das condições objetivas postas à realização da ação. Só podemos pensar o que/como fazer, se sabemos por que fazer e para que fazer, senão apenas fazemos por fazer.

Compreendendo esta unidade indissolúvel, podemos afirmar que,

[...] a dimensão técnico-operativa não pode ser reduzida à questão dos instrumentos e técnicas. Ela mobiliza as dimensões teórico-metodológicas - para analisar o real e investigar novas demandas - e ético-políticas - permitindo avaliar prioridades, as alternativas viáveis para a realização da ação, bem como projetar a ação em função dos valores e finalidade e avaliar as consequências dessa ação -, além das condições objetivas do trabalho e as condições subjetivas dos agentes profissionais. Acioná-la de modo consequente implica, também, em considerar as demandas colocadas pela população (SANTOS; SOUZA FILHO; BACKX, 2012, p. 19-20).

Destarte, entendemos que a dimensão técnico-operativa se apresenta na relação entre as "[...] estratégias e táticas definidas para orientar a relação profissional [...]” (PRÉDES, 2012, p. 87), as "[...] condições objetivas do trabalho profissional no cotidiano dos espaços sócio-ocupacionais [...]” (GUERRA, 2012, p. 34) e a "[...] orientação teórico-metodológica e ético-política dos agentes profissionais" (SANTOS; SOUZA FILHO; BACKX, 2012, p. 21).

A dimensão técnico-operativa também diz respeito "[...] às condições subjetivas dos agentes profissionais" (GUERRA, 2012, p. 35). Enquanto as condições objetivas do trabalho profissional são aquelas postas na realidade material, as condições subjetivas dos profissionais se referem aos sujeitos, ao seu grau de qualificação e preparo técnico e teórico-metodológico, bem como às suas escolhas, sempre na relação com as condições objetivas.

Desta maneira, pensar as três dimensões que conformam o exercício profissional, e a criação das condições para a clareza deste processo no trabalho dos assistentes sociais, nos remete 
diretamente a pensarmos a formação profissional de forma que esta consiga subsidiar o mesmo para uma intervenção crítica, qualificada, comprometida e competente técnica, teórica e eticamente.

\section{OS DESAFIOS DE PENSAR A DIMENSÃO TÉCNICA-OPERATIVA NA FORMAÇÃO PROFISSIONAL}

Entendemos como formação profissional o processo pelo qual estudantes de Serviço Social passam para se habilitarem ao trabalho profissional. É importante destacar que tal processo é contínuo e estende-se para a vida profissional de seus agentes, embora tenha seu início na graduação. A graduação é a base da formação profissional, e constitui um importante marco, já que é nela que o futuro assistente social terá seu primeiro contato com as três dimensões do trabalho profissional passando por um processo informativo e formativo que orientará sua ação.

Consideramos imperativo, portanto, apontar que por formação não compreendemos somente a "[...] oferta de disciplinas que propiciem uma titulação ao assistente social” (IAMAMOTO, 1992, p. 191). Compreendemos que as problematizações acerca da formação em Serviço Social devem ir além da lógica curricular formal, rebatendo na necessidade de "[...] preparar cientificamente quadros profissionais capazes de responder às exigências de um projeto profissional coletivamente construído e historicamente situado" (IAMAMOTO, 1998, p. 183).

Refletir sobre a formação que queremos, envolve necessariamente refletir sobre o perfil profissional desejado: dotado de competência para investigar e conhecer seu espaço de trabalho na realidade socioeconômica e política do país, além de habilitado teórica e metodologicamente (e, portanto, tecnicamente) para refletir sobre as implicações de sua atuação, sendo capaz de realizar escolhas conscientes e críticas, efetivando sua ação de forma criativa e propositiva diante das forças sociais que se apresentam.

[...] um profissional capaz de privilegiar a defesa dos direitos sociais, a ampliação da cidadania e a consolidação da democracia, com uma competência a ser adquirida nas várias dimensões que compõem o agir profissional: teórico-prática, técnica e éticooperativa. A formação profissional se configura, 
então, como um processo de qualificação teórico metodológico, técnico e ético-político para o exercício dessa especialização do trabalho coletivo (SANTOS, 2006, p. 60).

As Diretrizes Curriculares para os Cursos de Serviço Social materializam tal proposta de formação. Conforme afirmado anteriormente, tais diretrizes buscam romper com as abordagens unilaterais, com a cisão entre teoria e prática e atribuir ao projeto de formação profissional clara perspectiva ético-política. Tendo como parâmetros o Código de Ética do/a Assistente Social e a Lei de Regulamentação da Profissão, as diretrizes curriculares se juntam a esses dois documentos na sustentação do Projeto ÉticoPolítico Profissional.

Os pressupostos das Diretrizes deixam claro que o Serviço Social é uma profissão interventiva e atua nas expressões da questão social, sendo que a profissão se inscreve nas relações sociais de produção e reprodução da vida social. Em uma proposta curricular inovadora, as diretrizes estruturam um conjunto de conhecimentos inter-relacionados e sistematizados em três núcleos de fundamentação, que são compreendidos deforma a não admitir autonomia, linearidade e nem tratamento classificatório: pelo contrário, expressam diferentes níveis de apreensão da realidade social e do trabalho profissional, agregando um conjunto de conhecimentos indissociáveis para a apreensão da questão social, de suas particularidades na sociedade brasileira e de seu enfrentamento no âmbito da intervenção profissional.

Destarte, pode-se concluir que todos os conhecimentos abordados na graduação se voltam para a intervenção, na medida em que esta requisita níveis diferenciados de conhecimentos: teórico, político, ético e técnico, devendo contemplar todos eles. A qualificação operativa reforçada por tal projeto de formação "[...] se dá concomitantemente com saberes reflexivos e saberes interventivos [...]" (SANTOS; PINI, 2013, p. 139) exigindo também uma relação aproximada entre formação e realidade. Ao estabelecer como princípio formativo as dimensões investigativa e interventiva e a relação entre teoria e realidade como condição central da formação profissional, tal proposta recusa-se a fazer a separação entre ensino teórico e ensino prático, entre 
investigação e intervenção, entre ética e política, apontando o desafio da construção de uma metodologia de ensino que seja capaz de apreender tais aspectos em sua totalidade.

Embora a lógica das Diretrizes aponte na direção da não cisão entre fazer, pensar e escolher e reafirme o caráter interventivo da profissão, sabemos que sua operacionalização em cada unidade de ensino envolve diferentes desafios no que diz respeito as condições do ensino no Brasil, condições de trabalho na unidade de ensino, as perspectivas teóricas e políticas em cada unidade de ensino, ao entendimento dos docentes, entre outros.

Neste sentido, acreditamos que pensar a questão da dimensão técnico-operativa na formação em Serviço Social ainda se coloca como um desafio a ser enfrentado coletivamente pela categoria profissional. Um exemplo claro disso, é o fato que,

Os professores que ministram componentes curriculares cuja matéria diz respeito à operacionalização, aos conhecimentos procedimentais, se ressentem do escasso material com um referencial teórico crítico sobre essa dimensão e, principalmente, sobre os instrumentos e técnicas de intervenção (SANTOS; BACKX; GUERRA, 2012, p. 11).

A noção de uma formação de caráter teórico-prático é um grande desafio ao pensarmos a forma como as disciplinas incorporarão a discussão da intervenção profissional em sua transversalidade, assim como, a dimensão investigativa e a ética. Tal apreensão, no entanto, não descarta a necessidade do tratamento de elementos específicos do cotidiano do trabalho profissional em disciplinas específicas, bem como, em nosso entender, não suprime a necessária discussão e ensino da apropriação de instrumentos e técnicas que compõe o conjunto de atividades demandadas ao assistente social em seu cotidiano.

Desta forma, entendemos que materializar a proposta de ensino teórico-prático expressa nas Diretrizes necessariamente envolve o esforço de assegurar espaços para a discussão dos conhecimentos técnico-operativos, sempre garantindo a compreensão da unidade teoria-prática-ética que ocorre ao longo da formação profissional, mesmo que alguns componentes curriculares tratem mais 
especificamente da ação profissional. Isso significa que ainda que seja necessária a existência de unidades curriculares específicas ao trato da dimensão técnico-operativa do trabalho profissional, é necessário também que as demais unidades curriculares se realizem de maneira a concretizar a perspectiva teórico-prática defendida como fundamento da formação em Serviço Social.

Uma formação nesta direção só será possível se for clara e evidente, tanto no processo de organização curricular quanto no cotidiano da sala de aula, a compreensão de que todos os conhecimentos abordados na graduação servem como subsídios para a intervenção profissional e para a elaboração de metodologias de ação, uma vez que expressam a realidade em que o futuro profissional intervirá enquanto assistente social - e que conhecer a realidade é imprescindível para aqueles que se colocam dispostos a nela intervir - e mais que isso, transformá-la.

Para isso, é necessário enfrentar cotidianamente, os desafios postos aos diferentes sujeitos desta formação (estudantes, professores e supervisores de campo), estabelecendo processos contínuos de avaliação, diálogo e explicitação das dificuldades e acertos na construção de um ensino que supere as dicotomias aqui já anunciadas, bem como, aprofundar o debate e a produção do conhecimento sobre a dimensão técnico-operativa, de forma a criar mais subsídios que deem sustentação a este processo. Fundamental ainda, buscar criar estratégias e procedimentos no processo de ensino-aprendizagem que superem o modelo tradicional, que ainda temos na formação, com a tendência a separar as disciplinas práticas e as teóricas.

\section{CONSIDERAÇÕES FINAIS}

Conforme afirmamos até o momento, é fundamental pensarmos uma formação capaz de pautar-se na preparação de um profissional competente técnica, teórica e eticamente. O atual projeto de formação profissional em Serviço Social demarca tal necessidade, porém, como vimos, a questão da dimensão técnico-operativa ainda prescinde de aprofundamento e respostas no processo de ensino-aprendizagem em Serviço Social. Muitos são os desafios neste sentido! 
Importante destacar, que parte destes desafios está relacionada diretamente as condições do ensino na atualidade. O momento histórico em que acontece o processo de construção das Diretrizes curriculares é marcado pelo crescente desmonte das instituições federais de ensino superior e da eminente hegemonia das universidades privadas, seguida da eclosão dos cursos de ensino à distância. Analistas da política de educação superior apontam a hegemonia do setor privado no ensino superior no Brasil (GUERRA, 2010; CHAUÍ, 1999), evidenciando a dissonância entre a Política Nacional de Educação e a concepção de educação e de Universidade reafirmada pelo projeto de formação profissional defendido pelo Serviço Social - pública, gratuita, laica, presencial e de qualidade direcionada aos interesses da classe trabalhadora e enraizada na realidade regional e nacional, de forma a preservar a articulação entre ensino, pesquisa e extensão (CONSELHO FEDERAL DE SERVIÇO SOCIAL, 2011).

É nesse contexto que se trava um dos maiores desafios da formação profissional na atualidade: articular formação e mercado de trabalho. Tal articulação não significa a subordinação do projeto de formação às exigências do mercado, mas sim a busca por uma formação sintonizada com o mercado de trabalho, sem perder um distanciamento crítico do mesmo (IAMAMOTO, 1998). A formação profissional nestes moldes deve habilitar profissionais para que apreendam as demandas expressas pelas suas instituições empregadoras, tendo sempre como prioridade os usuários e as qualidades dos serviços prestados à população, sem nunca perder de vista as contradições e impasses pelos quais se realizam.

É necessário que o debate da formação profissional alcance a compreensão de que o posicionamento ético-político e a vinculação a correntes teóricas que fortaleçam os direitos sociais não são suficientes para garantí-los de fato, capacitando profissionais que contem com a competência necessária para materializar suas opções políticas e teóricas em ações que sejam coerentes com elas. Tal contexto fortalece um projeto de formação profissional subordinado às exigências do mercado (SANTOS, 2006), esvaziado de crítica e regido somente sob a lógica mercadológica do lucro (NETTO, 1996). 
Este mesmo contexto reverbera significativamente nas instituições empregadoras dos assistentes sociais e nas condições de vida da população usuária dos serviços sociosassistenciais. $\mathrm{O}$ arrefecimento do fundo público direcionado ao financiamento das políticas sociais incide diretamente na realidade em que acontece $o$ trabalho profissional, dando origem a instituições que demandam dos profissionais "[...] ações fragmentadas, imediatizadas e heterogêneas" (SANTOS; SOUZA FILHO; BACKX, 2012, p. 21).

Se a percepção dos assistentes sociais que recebem tais demandas não alcançar a reflexão sobre as determinações e conexões que as acompanham, tais quais "[...] o espaço onde o exercício profissional se realiza, as necessidades apresentadas pelos usuários e como a política social se realiza na organização [...]" (SANTOS; SOUZA FILHO; BACKX, 2012, p. 21), qualquer resposta profissional terá um fim em si mesma, ficando aquém de uma ação crítica, consciente e competente. O erro de tal postura incorre quando se valoriza o fazer por fazer; todavia, desconhecendo o significado social deste fazer, suas implicações éticas e políticas, seus resultados e a ausência deles.

Todavia, se os profissionais apenas refletirem sobre o que thes é demandado, sem contar com as habilidades necessárias para materializar suas reflexões em ações que sejam compatíveis com elas, os mesmos acabam por não realizar as suas competências, deixando de responder às demandas que lhes são postas.

Para formar profissionais capazes de responder às demandas que Ihes são postas, desenvolvendo suas ações com competência tornase cada vez mais urgente enriquecer o debate acerca da formação profissional, tecendo estratégias de resistência e de construção diante da lógica mercadológica presente em diferentes aspectos do trabalho e da formação profissional, traduzindo-as nos projetos de curso e nas construções político-pedagógicas em sala de aula.

Neste sentido, gostaríamos de terminar nossa reflexão, apresentando alguns pontos que acreditamos ser fundamentais a serem pensados na construção dos projetos políticos pedagógicos dos cursos em Serviço Social na perspectiva da concretização da transversalidade da investigação, intervenção e ética apregoada pelas diretrizes curriculares. É fundamental: 
- Possibilitar que as propostas curriculares consigam traduzir a questão do método materialista-histórico-dialético na lógica de articulação entre as disciplinas, explicitando tal articulação também em sala de aula;

- Construir metodologias de ensino que partam da apreensão deste método na forma de serem realizadas, incorporando elementos investigativos, reflexivos, artísticos e de contato direto com a realidade em todas as disciplinas;

- Realizar a articulação explícita entre a supervisão acadêmica de estágio e os demais conteúdos apreendidos no decorrer do curso;

- Realizar a discussão da dimensão técnico-operativa nas diferentes disciplinas, propiciando o contato dos estudantes com os instrumentos e técnicas comuns ao cotidiano profissional;

- Colocar o estudante em contato com o trabalho profissional, a partir de diferentes estratégias pedagógicas, desde o primeiro ano do curso, bem como, em contato com a realidade na apreensão das diferentes expressões da questão social regionalmente;

- Problematizar eticamente as questões postas na atual realidade e nos espaços sócio-ocupacionais do trabalho profissional.

Em síntese, é fundamental criar condições para a efetivação da lógica curricular proposta pelas diretrizes, realizando uma profunda reflexão sobre a transversalidade ali anunciada. Para tanto, há de se criar novas estratégias pedagógicas que levem em conta a unidade-diversa entre as três dimensões do trabalho profissional, o que significa, em nosso entender, criar um profundo processo de alteração da lógica formal que estamos acostumados. Pensar a formação de uma profissão interventiva sem cair no tecnicismo, mas, ao mesmo tempo sem subestimar a dimensão técnicooperativa nesta formação. Um desafio instigante à todos nós que acreditamos numa formação crítica, reflexiva e emancipatória em tempos de mercantilização do ensino, de reprodução acrítica dos paradigmas e avanços da perspectiva conservadora.

Que possamos seguir formando profissionais intransigentes, questionadores e preparados à responderem criticamente às demandas em seu exercício profissional! 


\section{REFERÊNCIAS}

CARDOSO, Priscila Fernanda Gonçalves. Ética e Projetos

Profissionais: os diferentes caminhos do Serviço Social no Brasil. Campinas: Papel Social, 2013.

CARDOSO, Priscila Fernanda Gonçalves. A Hegemonia do Projeto Profissional na década de 90: questionar é preciso, aderir (não) é preciso. 1999. 186 f. Dissertação (Mestrado)-Curso de Serviço Social, Pontifícia Universidade Católica de São Paulo, São Paulo, 1999.

CHAUI, Marilena. A universidade operacional. Folha de São Paulo, São Paulo, maio/1999. Caderno Mais! Disponível em: <http://www.cacos.ufpr.br/obras/Marilena_Chaui_Universidade_ Operacional.doc>. Acesso em: 12 nov. 2015.

CONSELHO FEDERAL DE SERVIÇO SOCIAL. CFESS Manifesta: Oficina Nacional da Abepss. 2011. Disponível em: <http://www. cfess.org.br/arquivos/cfessmanifesta2011_oficinaabepss_SITE. pdf>. Acesso em: 27 jun. 2017.

GUERRA, Yolanda. A dimensão técnico-operativa do exercício profissional. In: SANTOS, Cláudia Mônica dos; BACKX, Sheila; GUERRA, Yolanda (Org.). A Dimensão Técnico-operativa no Serviço Social: desafios contemporâneos. Juiz de Fora: UFJF, 2012. p. 39-70.

GUERRA, Yolanda. A formação profissional frente aos desafios da intervenção e das atuais configurações do ensino público, privado e a distância. Serviço Social \& Sociedade, São Paulo, n. 104, out. 2010. GUERRA, Yolanda. A instrumentalidade do Serviço Social. São Paulo: Cortez, 1995.

IAMAMOTO, Marilda Vilela. O Serviço Social na contemporaneidade: trabalho e formação profissional. São Paulo: Cortez, 1998.

IAMAMOTO, Marilda Vilela. Renovação e conservadorismo no Serviço Social: ensaios críticos. São Paulo: Cortez, 1992.

LESSA, S. O processo de produção-reprodução social: trabalho e sociabilidade. Capacitação em Serviço Social e política 
social. Módulo 2: Reprodução social, trabalho e Serviço Social. Brasília(DF): CFESS; ABEPSS; CEAD; UNB, 1999.

MARCONI, Marina de Andrade; LAKATOS, Eva Maria.

Metodologia do trabalho científico. 4. ed. São Paulo: Atlas, 1992.

MARX, Karl; ENGELS, Friederich. Tercer manuscrito. México:

Fondo de Cultura Económica, 1987. (Obras fundamentales 1. Marx. Escritos de juventud).

NETTO, José Paulo. Introdução ao estudo do método em Marx. São Paulo: Expressão Popular, 2011.

NETTO, José Paulo. Transformações Societárias e Serviço Social - notas para uma análise prospectiva da profissão no Brasil. Serviço Social \& Sociedade, São Paulo, n. 50, 1996.

NETTO, José Paulo; BRAZ, Marcelo. Economia política: uma introdução crítica. São Paulo, Cortez, 2006. (Col. Biblioteca Básica do Serviço Social, v.1).

PAIXÃO, Márcia Calhes. A política como objetivação: ontologia social, formação profissional e política. Caderno do Núcleo de Estudos e Aprofundamento Marxista, São Paulo, n. 1, 1997. PRÉDES, Rosa Lúcia. Ações Profissionais, Procedimentos e Instrumentos no Trabalho dos Assistentes Sociais nas Políticas Sociais. In: SANTOS, Cláudia Mônica dos; BACKX, Sheila; GUERRA, Yolanda (Org.). A Dimensão Técnico-operativa no Serviço Social: desafios contemporâneos. Juiz de Fora: UFJF, 2012. p. 69-103.

SANTOS, Claudia Monica dos. Os instrumentos e técnicas: mitos e dilemas na formação profissional do assistente social do Brasil. 2006. 251 f. Tese (Doutorado)-Curso de Programa de Pós Graduação em Serviço Social, Escola de Serviço Social, Universidade Federal do Rio de Janeiro, Rio de Janeiro, 2006.

SANTOS, Claudia Monica dos. Na prática a teoria é outra?: mitos e dilemas na relação entre teoria, prática, instrumentos e técnicas no Serviço Social. Rio de Janeiro: Lúmen Júris, 2010.

SANTOS, Claudia Mônica dos; PINI, Francisca. A transversalidade do ensino da prática na formação profissional 
do assistente social e o projeto Abepss Itinerante. Temporalis, Brasília (DF), n. 25, jan. 2013.

SANTOS, Cláudia Mônica dos; BACKX, Sheila; GUERRA, Yolanda (Org.). A dimensão técnico-operativa no Serviço Social: desafios contemporâneos. Juiz de Fora: UFJF, 2012. p. 15-39.

SANTOS, Cláudia Mônica dos; SOUZA FILHO, Rodrigo de; BACKX, Sheila. A dimensão técnico-operativa do Serviço Social: Questões para Reflexão. In: SANTOS, Cláudia Mônica dos; BACKX, Sheila; GUERRA, Yolanda (Org.). A dimensão técnico-operativa no Serviço Social: desafios contemporâneos. Juiz de Fora: UFJF, 2012. p. 15-39.

SARMENTO, Hélder Boska de Moraes. Instrumental Técnico e Serviço Social. In: SANTOS, Cláudia Mônica dos; BACKX, Sheila; GUERRA, Yolanda (Org.). A dimensão técnico-operativa no Serviço Social: desafios contemporâneos. Juiz de Fora: UFJF, 2012. p. 103-121.

VICENTE, Damares Pereira; CARDOSO, Priscila Fernanda Gonçalves. Manual, não; Metodologia, sim! Reflexões sobre metodologia no trabalho com famílias. In: CONGRESO BRASILEIRO DE ASSISTENTES SOCIAIS, 13., 2010, Brasília (DF). Anais em CD-Rom... Brasília (DF): CFESS; CRESS; ABEPSS; ENESSO, 2010. 